\title{
Production at the Curie Level of No-Carrier-Added 6-18F-Fluoro-L-Dopa
}

\author{
Lionel C. Libert ${ }^{1}$, Xavier Franci ${ }^{2}$, Alain R. Plenevaux ${ }^{1}$, Takashi Ooi ${ }^{3}$, Keiji Maruoka ${ }^{4}$, André J. Luxen ${ }^{1}$, \\ and Christian F. Lemaire ${ }^{1}$ \\ ${ }^{1}$ Cyclotron Research Center, Université de Liège, Liège, Belgium; ${ }^{2}$ GE Healthcare-MDx Chemistry System, Loncin, Belgium; \\ ${ }^{3}$ Department of Applied Chemistry, Graduate School of Engineering, Nagoya University, Nagoya, Japan; and ${ }^{4}$ Department of \\ Chemistry, Graduate School of Science, Kyoto University, Sakyo, Kyoto, Japan
}

\begin{abstract}
$6-{ }^{18} \mathrm{~F}$-fluoro-L-dopa ( $\left.{ }^{18} \mathrm{~F}-\mathrm{FDOPA}\right)$ has proven to be a useful radiopharmaceutical for the evaluation of presynaptic dopaminergic function using PET. In comparison to electrophilic synthesis, the no-carrier-added (NCA) nucleophilic method has several advantages. These include much higher available activity and specific activity. Recently, we have described an NCA enantioselective synthesis using a chiral phase-transfer catalyst. However, some chemicals were difficult to implement into a commercially available synthesizer, restricting access to this radiopharmaceutical to only a few PET centers. Methods: In this paper, 2 important chemical improvements are proposed to simplify production of ${ }^{18} \mathrm{~F}-\mathrm{FDOPA}$, resulting in straightforward automation of the synthesis in a commercially available module. Results: First, a fast, simple, and reliable synthesis of $2-{ }^{18} \mathrm{~F}$-fluoro-4,5-dimethoxybenzyl iodide on a solidphase support was developed. Second, a phase-transfer catalyst alkylation of a glycine derivative at room temperature was used to enable enantioselective carbon-carbon bond formation. After hydrolysis and high-performance liquid chromatography purification, a high enantiomeric excess of ${ }^{18}$ F-FDOPA $(\sim 97 \%)$ was obtained using a chiral catalyst available from a biphenyl $\mathbf{3}$ substrate. The total synthesis time was $63 \mathrm{~min}$, and the decay-corrected radiochemical yield was $36 \% \pm 3 \%(n=8)$. Conclusion: By exploiting the advantages of this NCA approach, using a starting activity of $185 \mathrm{GBq}$ of $\mathrm{NCA}{ }^{18} \mathrm{~F}$-fluoride, high activities of ${ }^{18} \mathrm{~F}$-FDOPA ( $>45$ $\mathrm{GBq}$ ) with high specific activity ( $\geq 753 \mathrm{GBq} / \mu \mathrm{mol})$ are now available at the end of synthesis for use in clinical investigations.
\end{abstract}

Key Words: ${ }^{18} \mathrm{~F}-\mathrm{FDOPA} ;{ }^{18} \mathrm{~F}$-fluoride; enantioselective; SPE; phasetransfer catalysis

J Nucl Med 2013; 54:1154-1161

DOI: 10.2967/jnumed.112.112284

$\mathbf{T}$

he radiopharmaceutical $6-{ }^{18} \mathrm{~F}-$-fluoro-L-dopa $\left({ }^{18} \mathrm{~F}-\mathrm{FDOPA}\right)$, an analogue of 3,4-dihydroxy-L-phenylalanine (L-dopa), has proven to be useful for human brain studies of the dopaminergic system using PET (1-4). PET studies using this important ${ }^{18} \mathrm{~F}$ fluorinated radiopharmaceutical allow visualization of the presynaptic

Received Sep. 14, 2012; revision accepted Jan. 22, 2013.

For correspondence or reprints contact: Christian F. Lemaire, Université de Liège, B-30, Centre de Recherches du Cyclotron, Sart Tilman, B-4000 Liège, Belgium.

E-mail: christian.lemaire@ulg.ac.be

Published online May 8, 2013.

COPYRIGHT @ 2013 by the Society of Nuclear Medicine and Molecular Imaging, Inc. distribution of the neurotransmitter dopamine and provide information on presynaptic dopamine metabolism. ${ }^{18} \mathrm{~F}$-FDOPA is used in the evaluation of neuropsychiatric disorders such as schizophrenia (5) and Alzheimer disease (6) and in studies of cognitive function (e.g., in Parkinson disease) $(4,7,8)$. More recently, ${ }^{18} \mathrm{~F}$ FDOPA has also been applied in oncology for the investigation of neuroendocrine tumors (9).

${ }^{18} \mathrm{~F}$-FDOPA is an aromatic amino acid with an asymmetric center. From a stereochemical point of view, this compound has 2 different 3-dimensional arrangements of atoms in space, nonsuperimposable on their mirror image, resulting in 2 enantiomers with D or $(R)$ and $\mathrm{L}$ or $(S)$ configuration. As the $\mathrm{D}$ isomer of ${ }^{18} \mathrm{~F}-$ FDOPA has a lower affinity for blood-brain barrier amino acid transport sites, enantiomeric purity is of great importance for PET imaging. Ideally, only the $\mathrm{L}$ form of ${ }^{18} \mathrm{~F}-\mathrm{FDOPA}$ should be synthesized (10).

Since the beginning of the 1980s, as the specific activity of the amino acid was not a critical parameter for biologic applications, synthesis of ${ }^{18} \mathrm{~F}$-FDOPA has generally been realized using an electrophilic approach. However, this synthesis was limited to PET centers with access to the ${ }^{20} \mathrm{Ne}(\mathrm{d}, \alpha){ }^{18} \mathrm{~F}$ nuclear reaction. So far, the most efficient electrophilic synthesis (radiochemical yield, $\sim 30 \%$ ) has been based on a 2-step protocol with an ${ }^{18} \mathrm{~F}$ fluorodestannylation reaction and subsequent deprotection of a protected tin L-derivative $(11,12)$. Based on this chemical pathway, a fully automated synthesis module is available for the routine clinical preparation of ${ }^{18} \mathrm{~F}$-FDOPA $(13,14)$. However, this electrophilic strategy produces only low amounts $(0.6-2.6 \mathrm{GBq})$ of $6-{ }^{18} \mathrm{~F}$-fluoro-L-dopa even when using expensive posttargetproduced ${ }^{18} \mathrm{~F}-\mathrm{F}_{2}$ (1.5 GBq) (15) or the "double-shoot" method (0.5 GBq) (16).

More recently, nucleophilic approaches have also been investigated and several enantioselective syntheses of ${ }^{18} \mathrm{~F}$-FDOPA from ${ }^{N C A}{ }^{18} \mathrm{~F}$-fluoride generated using the now-preferred ${ }^{18} \mathrm{O}(\mathrm{p}, \mathrm{n}){ }^{18} \mathrm{~F}$ reaction have been reported. Initially, $\mathrm{NCA}{ }^{18} \mathrm{~F}$-fluorination of the electron-rich aromatic ring of L-dopa was realized using a multistep approach (17-23). The most promising method requires a 3 -step synthesis of a small ${ }^{18} \mathrm{~F}$-fluoroaromatic compound that is used for phase-transfer catalyst enantioselective formation of a new carbon-carbon bond (21). As an alternative, an ${ }^{18} \mathrm{~F}$-for- ${ }^{19} \mathrm{~F}$ isotopic exchange reaction on a fully protected, masked, $\mathrm{L}^{-19} \mathrm{~F}-$ fluoroamino acid has been described (24). However, this approach produced ${ }^{18} \mathrm{~F}$-FDOPA with a low specific activity $(2 \mathrm{GBq} / \mu \mathrm{mol})$, after $105 \mathrm{~min}$ of synthesis and 2 subsequent transformation steps (Baeyer-Villiger oxidation and hydrolysis). 


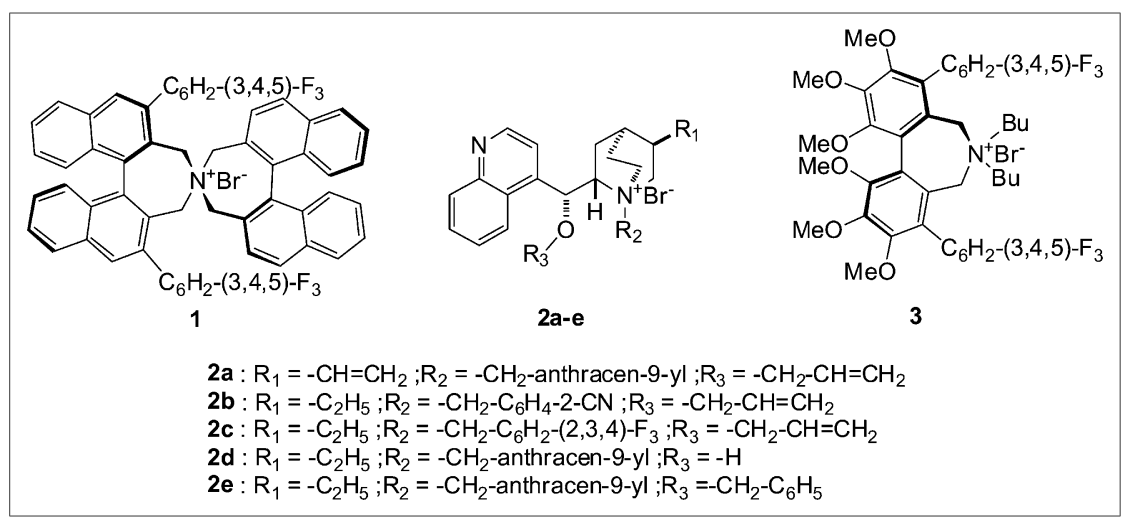

FIGURE 1. Chemical structure of 7 different chiral catalysts (1-3).

Recently, 2-step radiochemical syntheses (labeling and deprotection) of ${ }^{18} \mathrm{~F}$-FDOPA based on the nucleophilic substitution of an iodonium ylide or iodyl group of a protected L-dopa derivative have also been proposed $(25,26)$.

Presently, routine preparation of high specific activity $(>37$ $\mathrm{GBq} / \mu \mathrm{mol}){ }^{18} \mathrm{~F}-\mathrm{FDOPA}$ in our laboratory is achieved using a multistep phase-transfer catalyst strategy (21). However, some chemicals are difficult to implement in commercially available synthesizers. For example, synthesis of the ${ }^{18} \mathrm{~F}$-fluorobenzyl bromide (7 with bromine replacing iodine) with high yields requires the use of a corrosive gas $(\mathrm{HBr})$ that is arduous to handle and store. Moreover, the solid-phase support has to be kept "wet" with hexane before the halogenation step (21). Another limitation of this approach is the alkylation step, which necessitates a long precooling $(10 \mathrm{~min})$ of the electrophilic agent at $0^{\circ} \mathrm{C}$ before starting the enantioselective reaction $\left(10 \mathrm{~min}, 0^{\circ} \mathrm{C}\right)$. As a result, the complexity of the synthesis makes the production challenging, increasing the chance of failure in routine production if the synthesis is performed by untrained chemists. For large-scale clinical investigations and wider use of this radiopharmaceutical, progress in the automation of this complex radiosynthesis is a necessity. In this paper, 2 significant improvements to the chemistry in the production of ${ }^{18} \mathrm{~F}-\mathrm{FDOPA}$ are described, which have resulted in simplified automation of the synthesis in a FASTlab (GE Healthcare) synthesizer.

\section{MATERIALS AND METHODS}

\section{General}

6-fluoroveratraldehyde and other chemicals were purchased from standard commercial sources (ABCR, Acros, Apollo Scientific, and Aldrich). Kryptofix 222 (4,7,13,16,21,24-hexaoxa-1,10diazabicyclo[8.8.8] hexacosan), $\mathrm{KOH}, \mathrm{K}_{2} \mathrm{CO}_{3}$, and hydroiodic acid (HI, 57\%) were obtained from Merck. $N$-(diphenylmethylene)glycine tert-butyl ester $\mathbf{8}$ and cesium hydroxide monohydrate were purchased from Acros Organics. Before use, the hydriodic acid was distilled over red phosphorus and stored at $0^{\circ} \mathrm{C}$ after filtration. With the exception of this reagent, all commercially available chemicals were used without further purification. ${ }^{18} \mathrm{O}$-enriched water $\left(\mathrm{H}_{2}{ }^{18} \mathrm{O}>95 \%\right)$ was obtained from Rotem Industries. QMA Sep-Pak Light (130 mg) and tC18 (400 mg) Sep-Pak solid-phase extraction (SPE) cartridges were obtained from Waters. 2-formyl-4,5-dimethoxy- $N, N, N$-trimethylbenzenaminium trifluoromethanesulfonate $\mathbf{4}$ was synthesized according to procedures described in the literature (18) and characterized by standard methods. The ${ }^{19} \mathrm{~F}$-fluoro reference compounds were also prepared according to reported methods $(21,27)$. Chiral phase-transfer catalysts $\mathbf{2 a - 2 e}$ and 3 (Fig. 1) were prepared according to described methods $(21,28-31)$. Catalyst $\mathbf{1}$, a chiral spiro-type $(R, R)-3,4,5$-trifluorophenylNAS bromide, also known as the Maruoka catalyst (32), was initially provided by the Maruoka group (33) and was later obtained from a commercial source (Wako Pure Chemical Industries)

Thin-layer chromatography (TLC) was performed on Macherey Nagel Sil G/UV 254 silica plates with dichloromethane/EtOAc $(90 / 10)$ or dichloromethane $(100 \%)$. The radioactive spots were quantitatively analyzed on a Bioscan TLC scanner (model AR 2000). Radioactivity was measured in a dose calibrator, and all radiochemical yields were decay-corrected. The nonradioactive fluoro-compounds were used as reference on the same TLC plates and the ultraviolet spot detected at $254 \mathrm{~nm}$.

The TLC identity of the ${ }^{18} \mathrm{~F}$-labeled compounds was confirmed by high-performance liquid chromatography (HPLC) analysis after injection and coinjection on the same analytic HPLC system of the corresponding ${ }^{19} \mathrm{~F}$-fluorinated compounds (aldehyde 5, benzyl alcohol 6, benzyl iodide 7, and fluoroalkylated products 9). Analytic HPLC was performed with a Waters 600E pump, a manual Rheodyne injector $(20-\mu \mathrm{L}$ loop), a 996 Waters photodiode array detector, and the Empower chromatography manager software from Waters. For radioactivity detection, a $\mathrm{NaI}$ detector from Eberline was used. A symmetry Xterra RP18 column $(3.5 \mu \mathrm{m}, 4.6 \times 150 \mathrm{~mm}$; Waters $)$ was eluted with a mixture consisting of $\mathrm{CH}_{3} \mathrm{CN} /$ water (70/30) at a flow rate of $1 \mathrm{~mL} / \mathrm{min}$.

\section{Synthesis of 2-18F-Fluoro-4,5-Dimethoxybenzyl lodide 7}

NCA ${ }^{18} \mathrm{~F}$-fluoride was produced by proton irradiation $(18 \mathrm{MeV})$ of enriched ${ }^{18} \mathrm{O}$-water in a niobium or silver target $(2.2-\mathrm{mL}$ internal volume) using an IBA compact cyclotron $18 / 9$. The ${ }^{18} \mathrm{~F}$-fluoride was then transferred through Teflon (DuPont) tubing $(60 \mathrm{~m})$ to the chemistry laboratory and was trapped on a QMA Sep-Pak light cartridge. The ${ }^{18} \mathrm{~F}$-fluoride was then eluted from the solid support into the reaction vessel with a small volume $(500 \mu \mathrm{L})$ of a solution containing an equal volume of potassium carbonate in water $(7 \mathrm{mg} / 250 \mu \mathrm{L})$ and cryptand in acetonitrile $(22 \mathrm{mg} / 250 \mu \mathrm{L})$. The ${ }^{18} \mathrm{~F}$-fluoride was dried under a stream of nitrogen for $5 \mathrm{~min}$ on an aluminum heating block at $120^{\circ} \mathrm{C}$. At the end of the water $/ \mathrm{CH}_{3} \mathrm{CN}$ evaporation, a small additional volume of acetonitrile was added $(100 \mu \mathrm{L})$ and the mixture was concentrated to dryness. The azeotropic evaporation step was repeated twice $(2 \times 100 \mu \mathrm{L})$, and finally a dry fluorinating agent was obtained in the form of an ${ }^{18} \mathrm{~F}$-fluoride potassium Kryptofix complex $\left([\mathrm{K} / 222]^{+18} \mathrm{~F}^{-}\right)$. The ammonium substrate 4 in dimethyl sulfoxide $(800 \mu \mathrm{L}, 20 \mathrm{mg} / \mathrm{mL})$ was added to $0.1-185 \mathrm{GBq}$ of the dry residue of the $[\mathrm{K} / 222]^{+}{ }^{18} \mathrm{~F}^{-}$ complex. The vial was closed and the ${ }^{18} \mathrm{~F}$-labeling reaction was then conducted at $140^{\circ} \mathrm{C}$ for $2.5 \mathrm{~min}$. After labeling, the reaction solution was cooled and diluted with water $(30 \mathrm{~mL})$. The resulting solution was passed through a tC18 Sep-Pak cartridge previously activated with $5 \mathrm{~mL}$ of acetonitrile and $10 \mathrm{~mL}$ of water. The cartridge was then washed with $10 \mathrm{~mL}$ of water and dried for $15 \mathrm{~s}$ with a gentle flow of nitrogen.

Reduction of the ${ }^{18} \mathrm{~F}$-fluorinated aldehyde $\mathbf{5}$ was realized directly on the tC18 SPE cartridge by passing an aqueous solution of $\mathrm{NaBH}_{4}$ ( $3 \mathrm{~mL}, 6 \mathrm{mg} / \mathrm{mL}$ ) slowly through the cartridge $(21)$. Before the subsequent halogenation step, the cartridge was then washed with $5 \mathrm{~mL}$ of water and flushed for $15 \mathrm{~s}$ with a flow of nitrogen. For the conversion of the benzyl alcohol $\mathbf{6}$ to the benzyl halide 7, the activity was kept trapped on the support and $0.8 \mathrm{~mL}$ of an aqueous solution of $\mathrm{HI}(57 \%)$ 


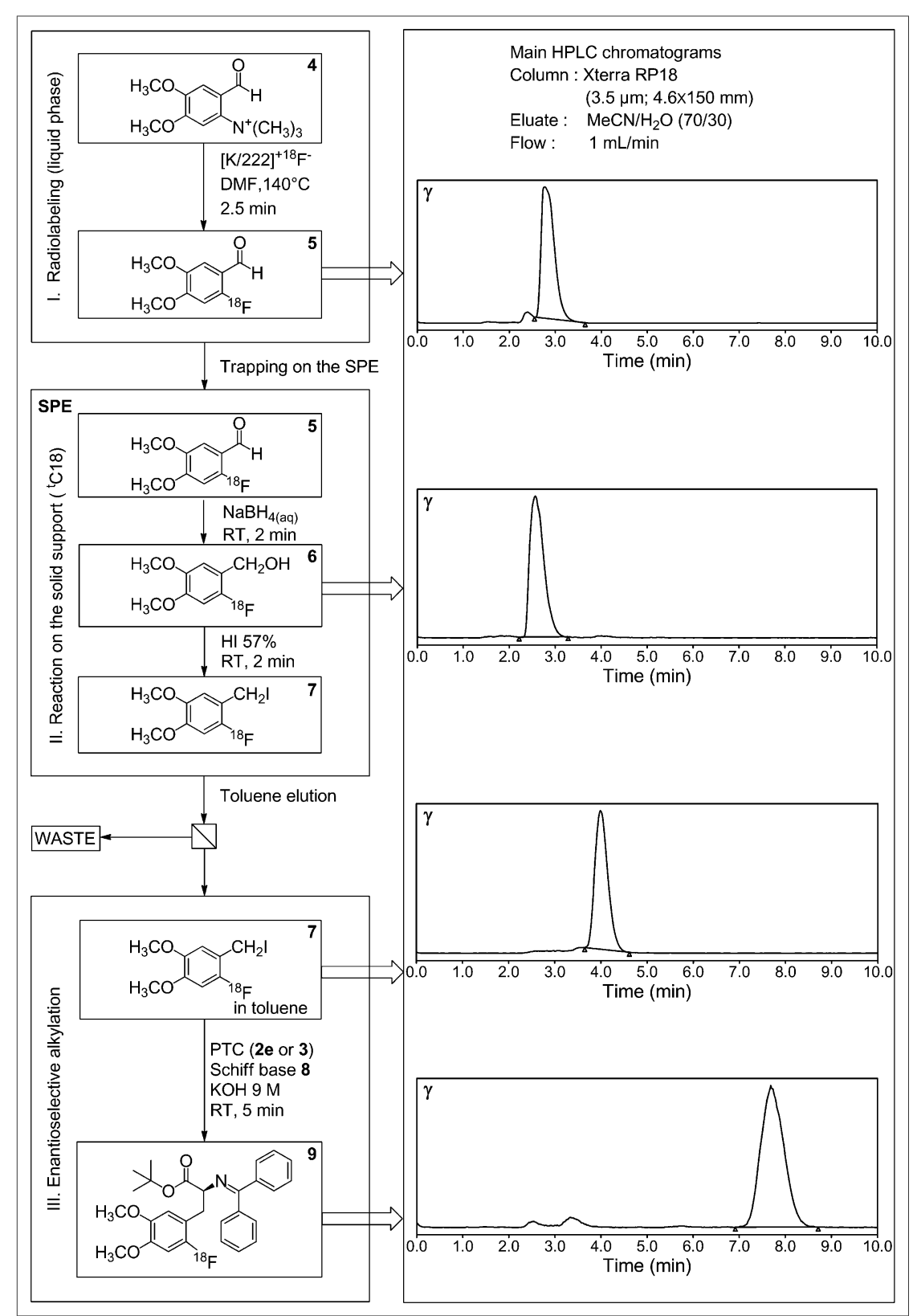

FIGURE 2. Typical radiochemical HPLC profiles of main steps of synthesis. DMF $=N, N$ dimethylformamide; PTC = phase-transfer catalyst; RT = room temperature.

\section{Alkylation, Hydrolysis, HPLC \\ Purification, and Formulation}

$2-{ }^{18}$ F-fluoro-4,5-dimethoxybenzyl iodide

7 in toluene was added to a vial containing the $N$-(diphenylmethylene)glycine tert-butyl ester $8(25 \mathrm{mg}, 85 \mu \mathrm{mol})$, the chiral phasetransfer catalyst $(2-3 \mathrm{mg}), \mathrm{CsOH} \cdot \mathrm{H}_{2} \mathrm{O}(150$ $\mathrm{mg}, 0.9 \mathrm{mmol})$, or $\mathrm{KOH}(9 \mathrm{M}, 200 \mu \mathrm{L})$. The reaction mixture was stirred vigorously at room temperature for $5 \mathrm{~min}$. A few microliters of the solution were then withdrawn and diluted with $\mathrm{CH}_{3} \mathrm{CN}$, and the $(S)-N$ (diphenylmethylene)-2-( $2^{\prime}{ }^{18}{ }^{18}$-fluoro- $4^{\prime}, 5^{\prime}$ dimethoxylbenzyl)-glycine tert-butyl ester 9 was analyzed by TLC and HPLC $\left(\mathrm{R}_{\mathrm{t}}\right.$ : $7.7 \mathrm{~min} ; \mathrm{R}_{\mathrm{f}}: 0.15,100 \%$ dichloromethane; $\mathrm{R}_{\mathrm{f}}: 0.70,90 / 10$ dichloromethane/AcOEt).

After the alkylation reaction, $\mathrm{HI}$ (57\%, 1 $\mathrm{mL})$ was added and the toluene evaporated at $180^{\circ} \mathrm{C}(3 \mathrm{~min})$. The reactor vial was then capped and the hydrolysis step conducted at this temperature for $15 \mathrm{~min}$. The reaction mixture was cooled to approximately $50^{\circ} \mathrm{C}$ and diluted with $4 \mathrm{~mL}$ of the semipreparative HPLC eluent.

The crude diluted hydrolysis mixture was loaded into a manual Rheodyne injector (6-mL loop). HPLC purification was performed using an Econosphere C18 column $(10 \mu \mathrm{m}, 250 \times$ $10 \mathrm{~mm}$; Grace) with a Waters 600 pump and a 996 Waters photodiode array detector (280 $\mathrm{nm}$ ) controlled by the Empower software. The radioactive elution profile was monitored with a custom-made Geiger-Müller radioactivity detector. The flow rate was $5 \mathrm{~mL} / \mathrm{min}$, and the mobile phase was aqueous acetic acid (50 $\mathrm{mM})$ at $\mathrm{pH} 4$ with ascorbic acid $(0.57 \mathrm{mM})$ and ethylenediaminetetraacetic acid $(1 \mathrm{mM})$. The retention time of the purified $6{ }^{18} \mathrm{~F}$-fluoro-L-dopa 10 was 9.3 min. The fraction containing ${ }^{18} \mathrm{~F}$-FDOPA was collected into a small vial containing $\mathrm{NaCl} 0.9 \%(30 \mathrm{~mL}), \mathrm{NaCl}$ $10 \%(0.5 \mathrm{~mL})$, and ascorbic acid $(30 \mathrm{mg})$.

For clinical use, the resulting solution was transferred to a pharmaceutical class A hot cell located inside the dispensing area, where microbiologic parameters are strictly controlled. The solution was filtered in a closed

was slowly passed through the support ( $2 \mathrm{~min}$ ). The reaction was conducted at room temperature. After reaction, the tC18 Sep-Pak was flushed with nitrogen for $30 \mathrm{~s}$ and the $2-{ }^{18} \mathrm{~F}$-fluoro-4,5-dimethoxybenzyl iodide 7 was eluted with toluene $(3 \mathrm{~mL}$ ) (dichloromethane and ether were also considered, as described in the "Results" section). The excess of acid and water was removed by passing the solution through a custom-made online potassium carbonate cartridge $(1.5 \mathrm{~g})$. The ${ }^{18} \mathrm{~F}$ fluorobenzyl iodide 7 , ready for subsequent alkylation reaction, was then recovered in about $2.5 \mathrm{~mL}$ of toluene.

The radiochemical yield and purity of the different products were determined by TLC and HPLC analyses after elution of the tC18 cartridge with $\mathrm{CH}_{3} \mathrm{CN}$. The retention times of the $6{ }^{-18} \mathrm{~F}$-fluoroveratraldehyde $\mathbf{5}, 2-{ }^{18} \mathrm{~F}$-fluoro-4,5-dimethoxybenzyl alcohol $\mathbf{6}$, and iodide 7 were $2.8 \mathrm{~min}$, $2.6 \mathrm{~min}$, and $4.0 \mathrm{~min}$, respectively (Fig. 2). (TLC: 90/10 dichloromethane/AcOEt; $\mathrm{R}_{\mathrm{f}} \mathrm{CHO}$ 5: $0.65 ; \mathrm{R}_{\mathrm{f}} \mathrm{CH}_{2} \mathrm{OH}$ 6: $0.3 ; \mathrm{R}_{\mathrm{f}} \mathrm{CH}_{2} \mathrm{I}$ 7: 0.74.) vial through 2 sterilizing $0.22-\mu \mathrm{m}$ membrane filters (Millex-GS; Millipore).

\section{Automation}

Except for the HPLC purification, all the steps of the synthesis were automated in a FASTlab module. This module was equipped with a second reactor heater that can be rapidly cooled if necessary. A new sequence, based on the chemistry improvements reported in this paper, was developed and the entire chemical process was performed with a single-use cassette. The fully automated radiosynthesis, with the exception of the HPLC purification, was performed in $52 \mathrm{~min}$ from the end of activity recovery from the cyclotron.

\section{Quality Control}

The enantiomeric purity of ${ }^{18} \mathrm{~F}$-FDOPA was determined after HPLC analysis on a CrownPak CR $(+)$ column $(5 \mu \mathrm{m}, 150 \times 4 \mathrm{~mm})$ from 


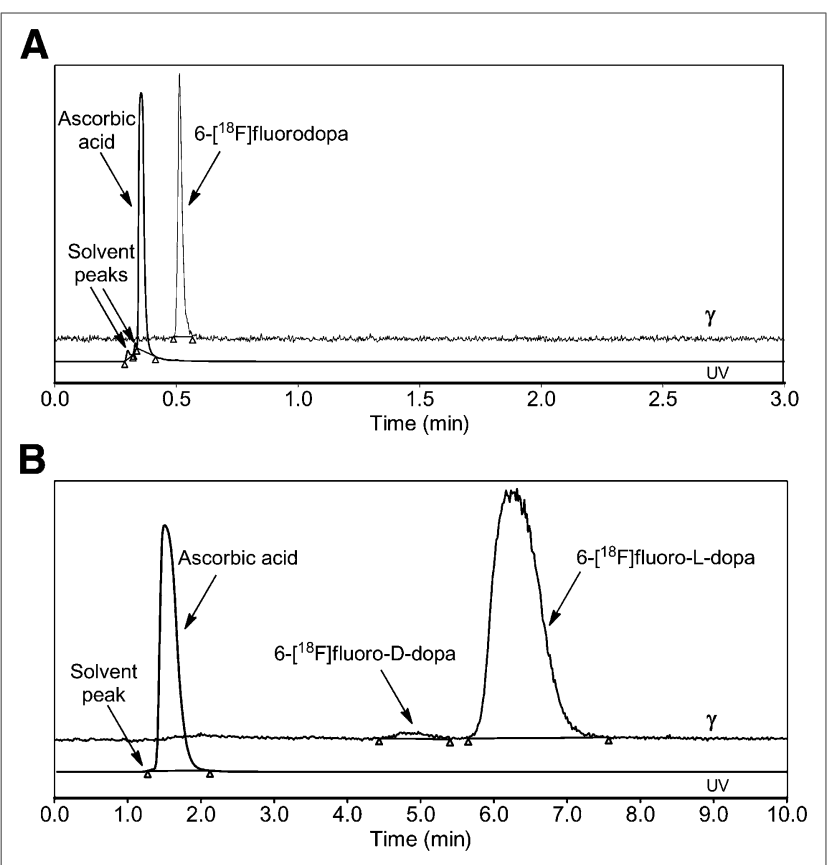

FIGURE 3. Quality chromatogram of final ${ }^{18} \mathrm{~F}-\mathrm{FDOPA}$. Typical UPLC (A) and HPLC (B) profiles (radiochemical $[\gamma]$ and ultraviolet [UV], $280 \mathrm{~nm})$. (A) Acquity BEH shield RP18 (1.7 $\mu \mathrm{m}, 2.1 \times 100 \mathrm{~mm})$; mobile phase: $\mathrm{H}_{2} \mathrm{O}, 0.8 \mathrm{~mL} / \mathrm{min}$. (B) Crownpack $\mathrm{CR}(+)(5 \mu \mathrm{m}, 150 \times$ $4 \mathrm{~mm}$ ); mobile phase: $\mathrm{HClO}_{4}$ (aqueous) $(\mathrm{pH} 2), 0.8 \mathrm{~mL} / \mathrm{min}$.

Daicel Chemical Industries. The mobile phase was an aqueous solution of $\mathrm{HClO}_{4}\left(\mathrm{pH} \mathrm{2.0)}\right.$, and the flow rate was $0.8 \mathrm{~mL} / \mathrm{min}\left(\mathrm{R}_{\mathrm{t}}: 5.0 \mathrm{~min}\right.$ [D] and $6.4 \mathrm{~min}$ [L]; Fig. 3B). Specific activity was determined by ultra-performance liquid chromatography (UPLC) quantification of an aliquot of the final sample of ${ }^{18} \mathrm{~F}-\mathrm{FDOPA}$ (ultraviolet and radioactive detectors). An ultraviolet calibration curve $(280 \mathrm{~nm})$ generated from solutions of known concentration was used to calculate the amount of cold ${ }^{19} \mathrm{~F}$-FDOPA (Research Biochemical International) in the radioactive sample. UPLC assay (ultraviolet set at $280 \mathrm{~nm}$ and radioactive detection) was performed at $50^{\circ} \mathrm{C}$ on a Acquity UPLC BEH shield RP18 column $(1.7 \mu \mathrm{m}, 2.1 \times 100 \mathrm{~mm}$; Waters $)$ eluted

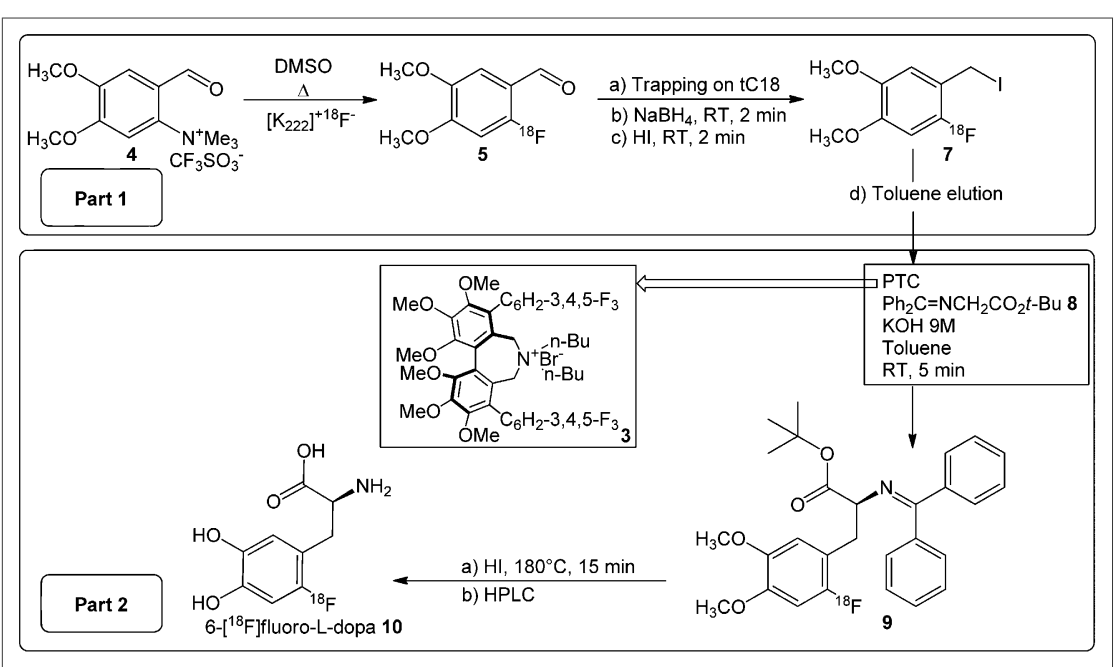

FIGURE 4. General phase-transfer catalyst strategy for radiochemical synthesis of $6-{ }^{18} \mathrm{~F}$ fluoro-L-dopa. DMSO = dimethyl sulfoxide; PTC = phase-transfer catalyst; RT = room temperature. at a flow rate of $0.8 \mathrm{~mL} / \mathrm{min}$ with water at $\mathrm{pH} 4(100 \%)$. The retention time was $0.51 \mathrm{~min}$.

\section{RESULTS}

The approach followed for the NCA radiochemical synthesis of 6- ${ }^{18}$ F-fluoro-L-dopa 10 (Fig. 4) is based on a similar pathway previously developed in our laboratory $(21,34)$.

The first part of the ${ }^{18} \mathrm{~F}$-FDOPA synthesis consisted of the preparation of a $2-{ }^{18} \mathrm{~F}$-fluoro-4,5-dimethoxybenzyl iodide 7 alkylating agent (part 1, Fig. 4). Briefly, fluorination of a trimethylammonium salt 4 was realized in dimethyl sulfoxide with ${ }^{18} \mathrm{~F}$-fluoride in the presence of the aminopolyether Kryptofix 222 and potassium carbonate. A radiochemical yield of $50 \%$ was obtained at $140^{\circ} \mathrm{C}$. After labeling, the aldehyde 4 was trapped on the SPE cartridge and reduced to the corresponding alcohol derivative $\mathbf{6}$ with a solution of $\mathrm{NaBH}_{4}$ in water. The $2-{ }^{18} \mathrm{~F}$-fluoro-4,5-dimethoxybenzyl alcohol 6 was converted to the iodide derivative 7 by passing an aqueous solution of hydroiodic acid (57\%) through the cartridge. The $2-{ }^{18}$ F-fluoro-4,5-dimethoxybenzyl iodide 7 was recovered from the SPE cartridge with a volume of toluene that did not exceed $2.5 \mathrm{~mL}$. NCA preparation of $2-{ }^{18} \mathrm{~F}$-fluoro-4,5-dimethoxybenzyl iodide 7 from the ammonium precursor $\mathbf{4}$ produces radiochemical yields of $42 \%-47 \%$ and high radiochemical purity ( $\geq 97 \%$ ) (Fig. 2).

The ${ }^{18} \mathrm{~F}$-fluorobenzyl iodide 7 recovered from the SPE and $\mathrm{K}_{2} \mathrm{CO}_{3}$ cartridges was directly used for the formation of the new carbon- $\alpha$ carbon- $\beta$ bond. The reaction was conducted at room temperature for $5 \mathrm{~min}$ in toluene with the prochiral Schiff base $\mathbf{8}$ in the presence of cesium hydroxide or potassium hydroxide (part 2, Fig. 4) and one of each of the chiral phase-transfer catalysts presented in Figure 1.

The radiochemical yield of the reaction was determined by HPLC and TLC ("Materials and Methods"). From these analyses, it appears that conversion of the benzyl iodide 7 into the ${ }^{18} \mathrm{~F}$ fluorobenzylated product 9 was nearly quantitative with all the catalysts investigated (>80\%-90\%) (Fig. 2). However, to obtain a short reaction time, effective and adequate mixing was crucial.

In all cases, the chiral efficiency of these phase-transfer catalysts and the enantiomeric excess of the ${ }^{18} \mathrm{~F}$-fluoro amino acid $\mathbf{1 0}$ (L isomer) were established after hydrolysis of the ${ }^{18} \mathrm{~F}$-fluorobenzylated product 9 and HPLC purification. The alkylation reaction was stopped by addition of $\mathrm{HI}(57 \%, 1 \mathrm{~mL})$, and the organic solvent was evaporated. After hydrolysis $\left(15 \mathrm{~min}, 180^{\circ} \mathrm{C}\right)$, the crude mixture was purified on a semipreparative HPLC column. Enantiomeric excesses were determined on an analytic HPLC chiral column ("Materials and Methods," Fig. 3B). The results obtained with catalysts $\mathbf{1}-\mathbf{3}$ are summarized in Table 1.

The effect of the temperature on the enantioselectivity of the reaction was evaluated between $25^{\circ} \mathrm{C}$ and $75^{\circ} \mathrm{C}$ with catalysts $2 \mathrm{e}$ and 3 (Fig. 5). These values were obtained after hydrolysis and HPLC purification.

The last step of the synthesis, before HPLC purification, requires evaporation of the toluene and hydrolysis of the protective groups. To facilitate automation of the evaporation step, the possibility of replacing 
TABLE 1

Enantiomeric Excess of ${ }^{18}$ F-FDOPA with Different Phase-Transfer Catalysts (1-3, Fig. 1)

\begin{tabular}{|c|c|c|c|c|}
\hline Entry & Catalyst & Base & Temperature $\left({ }^{\circ} \mathrm{C}\right)$ & Enantiomeric excess (\%) \\
\hline 1 & 1 & $\mathrm{CsOH} \cdot \mathrm{H}_{2} \mathrm{O}$ & $0^{\circ}$ & 96 \\
\hline 2 & 1 & $\mathrm{CsOH} \cdot \mathrm{H}_{2} \mathrm{O}$ & RT & 38 \\
\hline $3(21)$ & $2 a$ & $\mathrm{CsOH} \cdot \mathrm{H}_{2} \mathrm{O}$ & $0^{\circ}$ & 96 \\
\hline 4 & $2 a$ & $\mathrm{CsOH} \cdot \mathrm{H}_{2} \mathrm{O}$ & RT & 92 \\
\hline 5 & $2 a$ & $\mathrm{KOH} 9 \mathrm{~N}$ & RT & 93 \\
\hline 6 & $2 b$ & $\mathrm{KOH} 9 \mathrm{~N}$ & RT & 87 \\
\hline 7 & $2 c$ & $\mathrm{KOH} 9 \mathrm{~N}$ & RT & 84 \\
\hline 8 & $2 d$ & $\mathrm{KOH} 9 \mathrm{~N}$ & RT & 52 \\
\hline 9 & $2 e$ & $\mathrm{KOH} 9 \mathrm{~N}$ & RT & 97 \\
\hline 10 & 3 & $\mathrm{KOH} 9 \mathrm{~N}$ & RT & 97 \\
\hline
\end{tabular}

this solvent with another of lower boiling point was evaluated. These data were acquired with the biphenyl catalyst 3 (Table 2).

For preliminary automation in a FASTlab, the synthesis was performed using the $2{ }^{18} \mathrm{~F}$-fluoro-4,5-dimethoxybenzyl iodide 7 obtained from the ammonium salt $\mathbf{4}$, and the alkylation step was realized in toluene with catalyst $\mathbf{3}$, at room temperature, for $5 \mathrm{~min}$. After hydrolysis and HPLC purification, the collected peak of ${ }^{18} \mathrm{~F}-$ FDOPA was formulated to a final solution of $35 \mathrm{~mL}$ with $0.9 \%$ $\mathrm{NaCl}, 10 \% \mathrm{NaCl}$, and ascorbic acid.

Using this approach, the radiochemical yield of NCA ${ }^{18} \mathrm{~F}$ FDOPA was around $24 \%$ (not corrected for decay) after a little more than $1 \mathrm{~h}$ of synthesis $(63 \mathrm{~min}$ ). The enantiomeric excess was always greater than $96 \%$. The specific activity determined at the end of the synthesis on the sample without ascorbic acid was

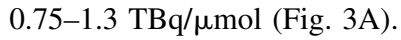

\section{DISCUSSION}

The multistep NCA nucleophilic approach described in this paper consists of 2 main parts. The first consists of the synthesis of a ${ }^{18}$ F-fluoro-labeled benzyl iodide 7 (part 1, Fig. 4), and the second, of the enantioselective alkylation of a prochiral protected derivative 8 by using a phase-transfer catalyst and a chiral catalyst, followed by hydrolysis and HPLC purification (part 2, Fig. 4).

The complexity of the synthesis makes automation challenging. To automate this synthesis on a FASTlab module, improvements to the 2 synthesis parts were necessary (Fig. 4).

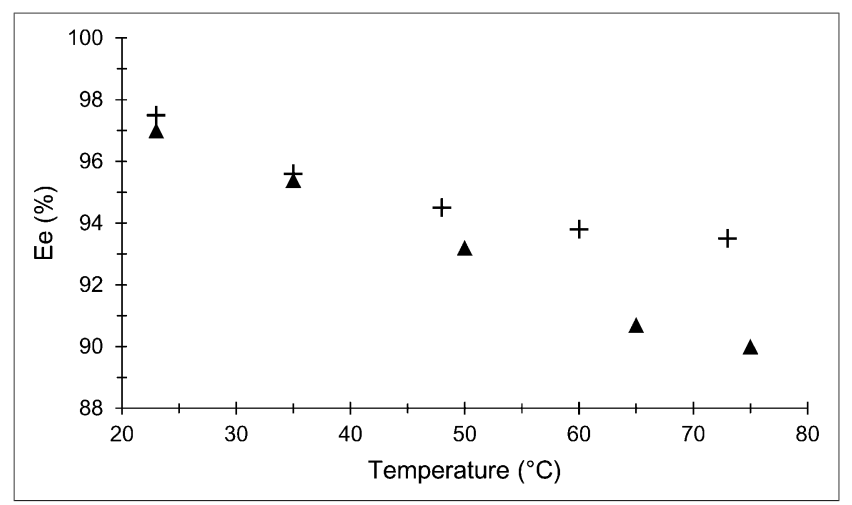

FIGURE 5. Effect of temperature on enantiomeric excess (Ee) of ${ }^{18}$ F-FDOPA with catalysts $2 \mathbf{e}(\mathbf{\Delta})$ and $\mathbf{3}(+)$.
The first part in the synthesis (part 1, Fig. 4) implies a 3-step preparation of a $2-{ }^{18} \mathrm{~F}$-fluoro-4,5-dimethoxybenzyl iodide 7 . According to previous results (27), its synthesis is feasible from either ammonium or nitro precursors with similar radiochemical labeling yields $(\sim 50 \%)$. However, the shorter reaction time of the ammonium salt 4 (2 min) than of the corresponding nitro compound ( $15 \mathrm{~min}$ ) can be considered a significant advantage in terms of available activity at the end of the process. In contrast to the nitro precursor, another advantage of this ammonium salt 4 results from its solubility in water. This solubility facilitates purification of the ${ }^{18} \mathrm{~F}$-fluorinated aldehyde $\mathbf{5}$ during the $\mathrm{tC} 18$ SPE trapping, allowing excess starting precursor to easily be removed.

The labeled aldehyde 5 was trapped on a tC18 SPE cartridge before being then quantitatively reduced into the corresponding alcohol 6 with an aqueous solution of $\mathrm{NaBH}_{4}$ (Fig. 2). We have recently shown that for the subsequent conversion of the benzyl alcohol 6 into the corresponding halogenated derivative, gaseous hydrogen bromide, which is difficult to handle, could be substituted by a concentrated aqueous solution of hydroiodic acid (27). This advantageous approach was then used for the preparation of the $2-{ }^{18} \mathrm{~F}$-fluoro-4,5-dimethoxybenzyl iodide 7 . According to typical HPLC profiles obtained during the synthesis, the reduction and iodination steps are nearly quantitative (Fig. 2).

In summary, this strategy greatly simplifies the synthesis and facilitates automation of the process by introducing fast reduction and halogenation steps at room temperature, on the same solid support, with easy-to-handle reagents $\left(\mathrm{NaBH}_{4}\right.$ [aqueous] and HI [57\%]).

The second part of the modified ${ }^{18}$ F-FDOPA synthesis described here entailed phase-transfer catalyst enantioselective construction of a new carbon-carbon single bond (part 2, Fig. 4) and the use of a chiral phase-transfer catalyst. To obtain high enantioselectivity, the $2-{ }^{18}$ F-fluoro-4,5-dimethoxybenzyl halide 7 in toluene must previously be cooled for at least $10 \mathrm{~min}$ at $0^{\circ} \mathrm{C}$ and the alkylation reaction conducted at this same temperature for 10 additional minutes (21). However, an alkylation reaction at this temperature is difficult to automate, because of the requirement for additional equipment such as a stirrer and a cooling system. To increase the overall radiochemical yield of the synthesis and to simplify automation, this alkylation should be performed at room temperature rather than at $0^{\circ} \mathrm{C}-\mathrm{a}$ temperature that should also 
TABLE 2

Effect of Solvent on Enantiomeric Excess of ${ }^{18} \mathrm{~F}-\mathrm{FDOPA}$

\begin{tabular}{lcc}
\hline \multicolumn{1}{c}{ Solvent } & $\begin{array}{c}\text { Boiling } \\
\text { point }\left({ }^{\circ} \mathrm{C}\right)\end{array}$ & $\begin{array}{c}\text { Enantiomeric } \\
\text { excess }(\%)\end{array}$ \\
\hline Dichloromethane & $39-40$ & 51.0 \\
\hline 1,2-dichloroethane & 83 & 46.5 \\
Diethyl ether & 34.6 & 97.3 \\
Diisopropyl ether & 68 & 97.5 \\
Cyclopentyl methyl & 106 & 97.5 \\
$\quad$ ether & & \\
Methyl tert-butyl ether & $55-56$ & 97.2 \\
Toluene & 111 & 97.5 \\
Xylenes & $136-140$ & 97.0 \\
\hline
\end{tabular}

Solvent ( $3 \mathrm{~mL})$, catalyst 3 ( $3 \mathrm{mg})$, Schiff base 8 ( $25 \mathrm{mg}), \mathrm{KOH} 9 \mathrm{~N}$ $(200 \mu \mathrm{L})$, room temperature, $5 \mathrm{~min}$.

improve synthesis time. The results of this second improvement are presented below.

Fortunately, in recent years, a great number of new chiral phasetransfer catalysts have been described $(30,35,36)$. A few of them with a potential high enantioselectivity at room temperature were evaluated. Their structures are illustrated in Figure 1.

All of these compounds are quaternary ammonium salts. Five of these new catalysts are cinchonidine derivatives with several substituents, including ethyl, anthracenyl, benzyl, allyl, or vinyl functions 2a-2e. Another has a conformationally fixed biphenyl core 3, and the last, which was commercially available at the beginning of this work, is a $\mathrm{C}_{2}$-symmetric chiral catalyst $\mathbf{1}$ that can be obtained after 11 synthesis steps from $(S)$-binaphthol.

With the exception of the Maruoka catalyst 1 (32), all these chiral catalysts have been synthesized in our laboratory. The synthesis of the cinchona alkaloid-derived phase-transfer catalysts is generally fast and requires only a limited number of steps ( 2 or 3 ) from the low-cost cinchonidine precursor available from the inexpensive chiral pool.

Catalysts 2a-2e have a common structure involving a sterically hindered tertiary amino group in a quinuclidine moiety, one alcohol function, and a quinoline structure. Depending of the stereostructure and type of functional groups, 4 generations of these catalysts are now described in the literature (37).

Catalyst 3 is certainly the most difficult to prepare. Its expensive preparation requires 6 steps from the resolved $(R)-4,5,6,4^{\prime}, 5^{\prime}$, 6 '-hexamethoxybiphenyl-2,2'-dicarboxylic acid, previously synthesized from commercially available 3,4,5-trimethoxybenzoic acid $(31,38)$.

All radiochemical alkylation reactions were conducted with similar amounts of catalyst $(2-3 \mathrm{mg} / 3-5 \mu \mathrm{mol})$. As shown in entries 1 and 2 of Table 1, summarizing enantiomeric excess for ${ }^{18}$ F-FDOPA, reaction temperature has a high effect on the enantioselectivity of the reaction with catalyst $\mathbf{1}$. An increase in temperature from $0{ }^{\circ} \mathrm{C}$ to room temperature decreases the enantiomeric excess from $96 \%$ to $38 \%$. Under the same conditions with catalyst $\mathbf{2 a}$, temperature has only a slight effect on enantiomeric excess (entries 3 and 4, Table 1).

With catalysts derived from cinchonidine 2a-2e (entries 3-9, Table 1), enantiomeric excesses of 52\%-97\% are obtained. A reaction performed using $9 \mathrm{~N}$ potassium hydroxide in place of $\mathrm{CsOH} \cdot \mathrm{H}_{2} \mathrm{O}$ produces a similar asymmetric induction at room temperature (entries 4 and 5, Table 1). Thus, to facilitate automation, all other experiments were conducted with $\mathrm{KOH}$. An enantiomeric excess of only $93 \%$ was observed with catalyst $\mathbf{2 a}$ at room temperature in toluene. This value is in accordance with the enantiomeric excess previously observed in our laboratory with dichloromethane and a greater amount of catalyst $(15 \mathrm{mg} / 25$ $\mu \mathrm{mol})(21,39)$. However, under the same conditions, enantiomeric excesses close to $100 \%$ have been reported $(19,40)$. In comparison, catalysts $\mathbf{2 c}$ (entry 7, Table 1 ) and $\mathbf{2 d}$ (entry 8, Table 1) produce relatively moderate enantioselectivity at room temperature. In this cinchonidine family, the highest enantioselectivity is obtained when cinchona is substituted by an ethyl, anthracenylmethyl, and benzyl function (entry 9, Table 1, catalyst 2e) (37).

A high enantioselectivity is also observed at room temperature with catalyst 3 (entry 10, Table 1). Under these conditions, $6-{ }^{18} \mathrm{~F}$-fluoro-L-dopa $\mathbf{1 0}$ is recovered with $97 \%$ enantiomeric excess. This value means that at least $98.5 \%$ of the $\mathrm{L}$ isomer and only $1.5 \%$ of the D are generated during the process. The enantiomeric excesses obtained with catalysts $\mathbf{3}$ and $\mathbf{2 e}(>95 \%)$ are similar.

In the literature, $\mathbf{3}$ is described as a catalyst with a very high catalytic activity, and very small amounts of $3(0.01 \mathrm{~mol} \%)$ are required for the benzylation of a Schiff base without decreasing the enantioselectivity of the reaction (35). Synthesis with cinchonidine derivatives requires generally $10 \mathrm{~mol} \%$. However, under our radiochemical conditions, both of these catalysts are always in large excess compared with the amount of NCA ${ }^{18} \mathrm{~F}$-fluorobenzyl iodide 7 used. This makes it difficult to evaluate the benefits of $\mathbf{3}$ compared with $\mathbf{2 e}$. At this NCA scale, the ratio of the different reagents (i.e., catalyst and Schiff base amount) used during the alkylation step can change the enantiomeric excess (21). Although this effect has been previously described, no attempts to optimize this reaction parameter were made in this study.

Enantiomeric excesses with catalysts $\mathbf{2 e}$ and $\mathbf{3}$ are similar at room temperature $(97 \%)$ and at $35^{\circ} \mathrm{C}(95.5 \%)$. However, increasing the reaction temperature to $75^{\circ} \mathrm{C}$ leads to a slight decrease in these values ( $90 \%$ and $93.5 \%$ enantiomeric excess, respectively) (Fig. 5). Compared with the first chiral catalysts described in the literature, these results are impressive.

As clearly shown in Table 2, chlorinated solvents are best avoided with catalyst $\mathbf{3}$ as they result in a low enantiomeric excess (maximum, 51\%). On the other hand, toluene (boiling point, $110^{\circ}$ C) could be replaced by an ethereal solvent of lower boiling point providing an enantiomeric excess of $96 \%$ or more (diethyl ether, diisopropyl ether, and methyl tert-butyl ether). However, the first automation with toluene in the FASTlab showed that this solvent could be evaporated in less than $5 \mathrm{~min}$, and thus replacing it is not of great importance.

Using this approach (Fig. 4) and a FASTlab module, automated synthesis of ${ }^{18} \mathrm{~F}$-FDOPA was realized in less than $65 \mathrm{~min}$ with a decay-corrected radiochemical yield of $36 \% \pm 3 \%(n=8)$. Nevertheless, the final decay-corrected radiochemical yield of this synthesis depends on the chemical purity of the starting ammonium salt 4, as this purity has a direct influence on the yield of the labeling step.

This approach included preparation of the $2-{ }^{18} \mathrm{~F}$-fluoro4,5-dimethoxybenzyl iodide $7(42 \%-47 \%, 25 \mathrm{~min})$, phasetransfer catalyst enantioselective alkylation with catalyst $\mathbf{3}$, hydrolysis, and HPLC purification and afforded ${ }^{18} \mathrm{~F}-\mathrm{FDOPA}$ with a high specific activity at the end of the synthesis $(0.75-1.3$ $\mathrm{TBq} / \mu \mathrm{mol})$. 
The injectable solution of ${ }^{18} \mathrm{~F}$-FDOPA contains ascorbic acid. This acts as a radical scavenger and contributes to the stability of the final solution. All quality control steps performed on the ${ }^{18} \mathrm{~F}$ FDOPA preparation met the basic criteria of the European Pharmacopeia. These included the appearance test, osmolarity (300 mOsm), $\mathrm{pH}$ (3.6), residual solvent (acetonitrile $<410 \mathrm{ppm}$; toluene $<890$ ppm; dimethyl sulfoxide $<5,000 \mathrm{ppm}$; acetic acid $<$ $5,000 \mathrm{ppm}$ ), enantiomeric purity (Fig. 3B), specific activity (Fig. 3A), half-life, and radionuclidic and radiochemical purities (Fig. 3A).

\section{CONCLUSION}

After application of the improvements to the chemistry described in this paper, the NCA synthesis of ${ }^{18} \mathrm{~F}-\mathrm{FDOPA}$ was greatly simplified. This is highlighted in, for example, the aldehyde 5 conversion into the corresponding alcohol $\mathbf{6}$ and iodide 7 derivatives, which is easily feasible on an SPE cartridge. After elution with a low volume of toluene, the ${ }^{18} \mathrm{~F}$-fluorobenzyl iodide 7 is ready to use in the subsequent alkylation step. This step, resulting in the enantioselective formation of a new carbon-carbon bond, proceeds readily at room temperature by phase-transfer catalyst in the presence of a chiral phase-transfer catalyst. This catalyst is readily available from a cinchonidine (2e) or biphenyl (3) substrate. In both cases, enantiomeric excesses were approximately $97 \%$.

Because of its operational simplicity and mild reaction conditions, the phase-transfer catalyst synthesis was easily implemented in a FASTlab module equipped with a second reactor heater. After $100 \mathrm{~min}$ of bombardment (185 GBq) and $63 \mathrm{~min}$ of synthesis, more than $45 \mathrm{GBq}$ (1.2 Ci) of 6- ${ }^{18}$ F-fluoro-L-dopa (enantiomeric excess $>96 \%$ ) with a specific activity in excess of $0.75 \mathrm{TBq} / \mu \mathrm{mol}$ are routinely produced with a reaction yield of $24 \%$.

With such reliable production, $6{ }^{18}$ F-fluoro-L-dopa is now available for clinical investigation.

\section{DISCLOSURE}

The costs of publication of this article were defrayed in part by the payment of page charges. Therefore, and solely to indicate this fact, this article is hereby marked "advertisement" in accordance with 18 USC section 1734. This work was supported by the Université de Liège and a GE grant. Alain Plenevaux is a research associate of FNRS Belgium. No other potential conflict of interest relevant to this article was reported.

\section{ACKNOWLEDGMENTS}

We thank the cyclotron operators Jean-Luc Genon and Patrick Hawotte for providing us with ${ }^{18} \mathrm{~F}$ and Geoffrey Warnock for useful discussions.

\section{REFERENCES}

1. Egerton A, Demjaha A, McGuire P, Mehta MA, Howes OD. The test-retest reliability of ${ }^{18} \mathrm{~F}$-DOPA PET in assessing striatal and extrastriatal presynaptic dopaminergic function. Neuroimage. 2010;50:524-531.

2. Elsinga PH, Hatano K, Ishiwata K. PET tracers for imaging of the dopaminergic system. Curr Med Chem. 2006;13:2139-2153.

3. Garnett ES, Firnau G, Nahmias C. Dopamine visualized in the basal ganglia of living man. Nature. 1983;305:137-138.

4. Minn H, Kauhanen S, Seppanen M, Nuutila P. ${ }^{18}$ F-FDOPA: a multiple-target molecule. J Nucl Med. 2009;50:1915-1918.
5. Patel NH, Vyas NS, Puri BK, Nijran KS, Al-Nahhas A. Positron emission tomography in schizophrenia: a new perspective. J Nucl Med. 2010;51: 511-520.

6. Kumakura Y, Danielsen EH, Gjedde A, et al. Elevated $\left[{ }^{18} \mathrm{~F}\right] \mathrm{FDOPA}$ utilization in the periaqueductal gray and medial nucleus accumbens of patients with early Parkinson's disease. Neuroimage. 2010;49:2933-2939.

7. Gallagher CL, Johnson SC, Bendlin BB, et al. A longitudinal study of motor performance and striatal $\left[{ }^{18} \mathrm{~F}\right]$ fluorodopa uptake in Parkinson's disease. Brain Imaging Behav. 2011;5:203-211.

8. Klein JC, Eggers C, Kalbe E, et al. Neurotransmitter changes in dementia with Lewy bodies and Parkinson disease dementia in vivo. Neurology. 2010;74:885892.

9. Fiebrich H-B, Jong JR, Kema IP, et al. Total ${ }^{18} \mathrm{~F}$-dopa PET tumour uptake reflects metabolic endocrine tumour activity in patients with a carcinoid tumour. Eur J Nucl Med Mol Imaging. 2011;38:1854-1861.

10. Oldendorf WH. Stereospecificity of blood-brain barrier permeability to amino acids. Am J Physiol. 1973;224:967-969.

11. Namavari M, Bishop A, Satyamurthy N, Bida G, Barrio JR. Regioselective radiofluorodestannylation with $\left[{ }^{18} \mathrm{~F}\right] \mathrm{F} 2$ and $\left[{ }^{18} \mathrm{~F}\right] \mathrm{CH}_{3} \mathrm{COOF}$ : a high yield synthesis of 6-[ $\left.{ }^{18} \mathrm{~F}\right]$ fluoro-L-dopa. Int J Rad Appl Instrum A. 1992;43: 989-996.

12. Dolle F, Demphel S, Hinnen F, Fournier D, Vaufrey F, Crouzel C. 6- $\left[{ }^{18} \mathrm{~F}\right]$ fluoro-L-DOPA by radiofluorodestannylation: a short and simple synthesis of a new labeling precursor. J Labelled Comp Radiopharm. 1998;41: $105-114$.

13. De Vries EFJ, Luurtsema G, Brüssermann M, Elsinga PH, Vaalburg W. Fully automated synthesis module for the high yield one-pot preparation of $6-\left[{ }^{18} \mathrm{~F}\right]$ fluoro-L-DOPA. Appl Radiat Isot. 1999;51:389-394.

14. Kao C-HK, Hsu W-L, Xie H-L, Lin M-C, Lan W-C, Chao H-Y. GMP production of $\left[{ }^{18} \mathrm{~F}\right] \mathrm{FDOPA}$ and issues concerning its quality analyses as in USP "fluorodopa F 18 injection." Ann Nucl Med. 2011;25:309-316.

15. Forsback S, Eskola O, Haaparanta M, Bergman J, Solin O. Electrophilic synthesis of $6-\left[{ }^{18} \mathrm{~F}\right]$ fluoro-L-DOPA using post-target produced $\left[{ }^{18} \mathrm{~F}\right] \mathrm{F} 2$. Radiochim Acta. 2008;96:845-848.

16. Azad BB, Chirakal R, Schrobilgen GJ. Trifluoromethanesulfonic acid, an alternative solvent medium for the direct electrophilic fluorination of DOPA: new syntheses of 6-[ ${ }^{18}$ F]fluoro-L-DOPA and 6-[ ${ }^{18}$ F $]$ fluoro-D-DOPA. J Labelled Comp Radiopharm. 2007;50:1236-1242.

17. Lemaire C, Plenevaux A, Cantineau R, Christiaens L, Guillaume M, Comar D. Nucleophilic enantioselective synthesis of $6-\left[{ }^{18} \mathrm{~F}\right]$ fluoro-L-dopa via two chiral auxiliaries. Appl Radiat Isot. 1993;44:737-744.

18. Lemaire C, Damhaut P, Plenevaux A, Comar D. Enantioselective synthesis of 6-[fluorine-18]-fluoro-L-dopa from no-carrier-added fluorine-18-fluoride. J Nucl Med. 1994;35:1996-2002.

19. Yin D, Zhang L, Tang G, Tang X, Wang Y. Enantioselective synthesis of nocarrier added (NCA) 6-[ ${ }^{18}$ F]fluoro-L-dopa. J Radioanal Nucl Chem. 2003;257: $179-185$.

20. Krasikova RN, Zaitsev VV, Ametamey SM, et al. Catalytic enantioselective synthesis of ${ }^{18} \mathrm{~F}$-fluorinated $\alpha$-amino acids under phase-transfer conditions using (s)-NOBIN. Nucl Med Biol. 2004;31:597-603.

21. Lemaire C, Gillet S, Guillouet S, Plenevaux A, Aerts J, Luxen A. Highly enantioselective synthesis of no-carrier-added $6-\left[{ }^{18} \mathrm{~F}\right]$ fluoro-L-DOPA by chiral phasetransfer alkylation. Eur J Org Chem. 2004;2899-2904.

22. Krasikova RN, Kuznetsova OF, Fedorova OS, et al. Asymmetric synthesis of $6-{ }^{18}$ F-L-FDOPA using chiral nickel(II) complexes. Radiochemistry. 2007;49: $512-518$.

23. Shen B, Ehrlichmann W, Uebele M, Machulla HJ, Reischl G. Automated synthesis of n.c.a. $\left[{ }^{18} \mathrm{~F}\right] \mathrm{FDOPA}$ via nucleophilic aromatic substitution with $\left[{ }^{18} \mathrm{~F}\right]$ fluoride. Appl Radiat Isot. 2009;67:1650-1653.

24. Wagner FM, Ermert J, Coenen HH. Three-step, "one-pot" radiosynthesis of 6-fluoro-3,4-dihydroxy-L-phenylalanine by isotopic exchange. J Nucl Med. 2009;50:1724-1729.

25. DiMagno SG, inventor; Nutech Ventures USA, assignee. A process for the preparation of arylfluoride derivatives. U.S. patent US20110313170A1, December 22, 2011.

26. Satyamurthy N, Barrio JR, inventors; University of California, USA, assignee. No-carrier-added nucleophilic $\left[{ }^{18} \mathrm{~F}\right]$-fluorination of aromatic compounds using phenyliodonium ylides. U.S. patent WO2010117435A2, April 1, 2010 .

27. Lemaire C, Libert L, Plenevaux A, Aerts J, Franci X, Luxen A. Fast and reliable method for the preparation of ortho- and para- $\left[{ }^{18} \mathrm{~F}\right]$ fluorobenzyl halide derivatives: key intermediates for the preparation of no-carrier-added PET aromatic radiopharmaceuticals. J Fluor Chem. 2012;138:48-55. 
28. Jew S-S, Yoo M-S, Jeong B-S, Park IY, Park H-G. An unusual electronic effect of an aromatic-F in phase-transfer catalysts derived from cinchona-alkaloid. Org Lett. 2002;4:4245-4248.

29. Yoo M-S, Jeong B-S, Lee J-H, Park H-G, Jew S-S. Evidence of the electronic factor for the highly enantioselective catalytic efficiency of Cinchona-derived phase-transfer catalysts. Org Lett. 2005;7:1129-1131.

30. Lygo B, Beaumont DJ. Two highly effective phase-transfer catalysts for the enantioselective synthesis of $\alpha$-amino acid derivatives. Chimia. 2007;61: 257-262.

31. Wang Y-G, Ueda M, Wang X, Han Z, Maruoka K. Convenient preparation of chiral phase-transfer catalysts with conformationally fixed biphenyl core for catalytic asymmetric synthesis of $\alpha$-alkyl- and $\alpha, \alpha$-dialkyl- $\alpha$-amino acids: application to the short asymmetric synthesis of BIRT-377. Tetrahedron. 2007; 63:6042-6050.

32. Maruoka K. Highly practical amino acid and alkaloid synthesis using designer chiral phase transfer catalysts as high-performance organocatalysts. Chem Rec. 2010;10:254-259.

33. Maruoka K. Design of C2-symmetric chiral phase-transfer catalysts for practical asymmetric synthesis. Chimia. 2007;61:263-268.
34. Lemaire C, Gillet S, Ooi T, et al. Enantioselective synthesis of $2-\left[{ }^{18} \mathrm{~F}\right]$ fluoro-Ltyrosine by catalytic phase-transfer alkylation. J Labelled Comp Radiopharm. 2001;44(suppl):S857-S859.

35. Ooi T, Maruoka K. Recent advances in asymmetric phase-transfer catalysis. Angew Chem Int Ed Engl. 2007;46:4222-4266.

36. Corey EJ, Xu F, Noe MC. A rational approach to catalytic enantioselective enolate alkylation using a structurally rigidified and defined chiral quaternary ammonium salt under phase transfer conditions. J Am Chem Soc. 1997;119:12414-12415.

37. Jew S-S, Park H-G. Cinchona-based phase-transfer catalysts for asymmetric synthesis. Chem Commun (Camb). 2009;7090-7103.

38. Han Z, Yamaguchi Y, Kitamura M, Maruoka K. Convenient preparation of highly active phase-transfer catalyst for catalytic asymmetric synthesis of $\alpha$-alkyl- and $\alpha, \alpha$-dialkyl- $\alpha$-amino acids: application to the short asymmetric synthesis of BIRT-377. Tetrahedron Lett. 2005;46:8555-8558.

39. Lemaire C, Guillouet S, Plenevaux A, Brihaye C, Aerts J, Luxen A. The synthesis of $6-\left[{ }^{18} \mathrm{~F}\right]$ fluoro-L-dopa by chiral catalytic phase-transfer alkylation. J Labelled Comp Radiopharm. 1999;42(suppl 1):S113-S115.

40. Zhang L, Tang G, Yin D, Tang X, Wang Y. Enantioselective synthesis of no-carrier-added (NCA) 6-[ ${ }^{18}$ F]fluoro-L-DOPA. Appl Radiat Isot. 2002;57: 145-151. 